\title{
CEJOR special issue of Croatian Operational Research Society
}

\author{
Marijana Zekić-Sušac ${ }^{1}$ - Rudolf Scitovski ${ }^{2}$. \\ Goran Lešaja ${ }^{3}$
}

Published online: 14 June 2018

(C) Springer-Verlag GmbH Germany, part of Springer Nature 2018

We are very glad to introduce this first special issue of the Croatian Operational Research Society, which was established in 1992 and has a fruitful collaboration with the Central European Journal of Operational Research since its inception.

The area of OR has been one of the core subjects at Croatian universities decades ago. In today's age of advanced computing technologies that are able to process large quantities of data, it is becoming even more attractive and involved. Croatian Operational Research Society gathers more than 150 researchers with the mission to promote operational research in Croatia and worldwide which has been realized through several goals: (1) to encourage collaboration of scientists and researchers in the area of operational research in Croatia and worldwide through seminars, conferences, lectures and other ways of collaboration, (2) to organize the International Conference on Operational Research (KOI), and (2) to publish scientific journal Croatian Operational Research Review (CRORR). Since 1994, CRORS is a member of the Association of

$凶 \quad$ Marijana Zekić-Sušac

marijana@efos.hr

Rudolf Scitovski

scitowsk@mathos.hr

Goran Lešaja

goran@georgiasouthern.edu

1 Faculty of Economics, University of Josip Juraj Strossmayer in Osijek, Trg Lj. Gaja 7, 31000 Osijek, Croatia

2 Department of Mathematics, University of Josip Juraj Strossmayer in Osijek, Trg Lj. Gaja 6, 31000 Osijek, Croatia

3 Department of Mathematical Sciences, Georgia Southern University, 65 Georgia Avenue, Statesboro, GA 30460 - 8093, USA 
European Operational Research Societies (EURO) and the International Federation of Operational Research Societies (IFORS), and actively participates in their activities. The contribution of CRORS was rewarded in 2008 by a Charter of recognition from Elise A. del Rosario, the president of EURO at that time. On the occasion of publishing this special issue, we would like to thank the former presidents of CRORS: Luka Neralić, Tihomir Hunjak, Kristina Šorić, Valter Boljunčić, and Zoran Babić, as well as to other members of CRORS for their efforts in developing the society and its impact in OR research. The CRORS has organized 16 international conferences KOI so far in different cities in Croatia, and continuously publishes Croatian Operational Research Review journal (now included in relevant databases such as WoS ESCI and Scopus), as well as CRORS News Magazine.

The sixteen (16) papers in this issue bring into the light some recent research results of CRORS members and their international collaborators. There are four (4) papers in honor of Goran Lešaja's birthday that cover various optimization problems and methods. The paper written by Csizmadia et al. (2018) considers the primal quadratic simplex method for linearly constrained convex quadratic programming problems. The paper of Darvay and Takács (2018) proposes a large-step IPM in the new wide neighborhood of the central path for. In the paper Cvetković et al. (2017) discuss some new complexity indices for traveling salesman problem (TSP). The paper of Peric et al. (2018) suggests a new method based on the cooperative game theory (MP method) and compare its efficiency with a STEM method.

There is a group of papers in the area of multicriteria optimization such as the paper of Targiel et al. (2018) which suggests a model for scheduling non-critical activities under uncertainty and follows up some previous results of multicriteria optimization under uncertainty published in CEJOR (Gaspars-Wieloch 2017). Uncertainty was also the subject in the paper of Kvet and Janáček (2017) who compare scenario and fuzzy values approaches. Kadoić et al. (2018) propose a new method for strategic decision making in higher education based on the analytical network process (ANP) and social network analysis (SNA) using centrality measures which were also discussed in previous issues of CEJOR (Csató 2017). Kojić and Lukač (2018) suggest an alternative approach to solving cost minimization problem with Cobb-Douglas technology based on weighted arithmetic-geometric mean inequality without using calculus. The two papers in this issue propose new approaches for using optimization algorithms and clustering in the domain of policy; Marošević and Soldo (2018) suggest a modification for calculating indices of political power within a parliament, while Jelić and Ševerdija (2017) provide a model inspired by the team formation problem in a social network that suggests a subset of candidates for positions in the new government using integer linear programming.

One of the frequent topics among Croatian OR researchers is the Data Envelopment Analysis (DEA) in various domains. The paper of Borozan and Borozan (2018) explores the total-factor energy efficiency and change trends in technical efficiency in the Croatian counties by DEA, while Gardijan and Lukač (2018) use DEA to measure relative efficiency of food and drink industry in EU.

The paper of Majstorović et al. (2018) deals with graph theory, namely growth curve clustering problem, and analyzes its connection with the spectral relaxation method, showing that the eigendecomposition of a specific matrix associated with a 
similarity graph can be a solution. There are two papers in the area of statistics. The paper of Hamedović et al. (2018) estimates the size of an object from a noisy image by using two one-dimensional parametric models to construct confidence intervals and statistical tests. Kramarić et al. (2018) use nonhierarchical cluster analysis to explore insurance companies in selected post-transition countries. Finally, this issue contains a paper that deals with mapping of seismic parameters of the Iberian Peninsula by means of a geographic information system (Amaro-Mellado et al. 2018).

It is worth to mention that some of the authors in this special issues are young researchers such as Jelić and Ševerdija (2017) who were awarded with the Best Student Research Paper Award at KOI 2016 conference. The special issue contains papers with wide range of relevant and contemporary topics in the area of OR which were also discussed by other authors in previous issues of this journal and other OR journals, such as the topics of IPM (Meszaros 2015), multicriteria optimization (Trdin and Bohanec 2018), social network analysis (Csató 2017), game theory (Aust and Buscher 2016; McCormick and Owen 2018). DEA (Šegota et al. 2017), clustering (Scitovski et al. 2017), and graph theory (Vinkó and Gelle 2017).

The collaboration and exchange of ideas is one of the key factors of success and development in modern science. We believe that Croatian OR Society researchers engaging in collaboration and cooperation with each other and with researchers from other OR societies will continue to produce high quality research results and advance the field of OR in Croatia and abroad. We hope that this Special Issue is a good representation of such efforts and will spark interest and future research in featured areas and beyond.

Osijek, April 2018.

\section{References}

Amaro-Mellado JL, Morales-Esteban A, Martínez-Álvarez F (2018) Mapping of seismic parameters of the Iberian Peninsula by means of a geographic information system. CEJOR. https://doi.org/10.1007/s10 100-017-0506-7

Aust G, Buscher U (2016) Game theoretic analysis of pricing and vertical cooperative advertising of a retailer-duopoly with a common manufacturer. CEJOR 24:127. https://doi.org/10.1007/s10100-0140338-7

Borozan D, Borozan L (2018) Analyzing total-factor energy efficiency in Croatian counties: evidence from a nonparametric approach. CEJOR. https://doi.org/10.1007/s10100-017-0493-8

Csató L (2017) Measuring centrality by a generalization of degree. CEJOR 25:771. https://doi.org/10.100 7/s10100-016-0439-6

Csizmadia A, Csizmadia Z, Illés T (2018) Finiteness of the quadratic primal simplex method when smonotone index selection rules are applied. CEJOR. https://doi.org/10.1007/s10100-018-0523-1

Cvetković D, Čangalović M, Dražić Z, Kovačević-Vujčić V (2017) Complexity indices for the traveling salesman problem based on short edge subgraphs. CEJOR. https://doi.org/10.1007/s10100-017-051 3-8

Darvay Z, Takács PR (2018) Large-step interior-point algorithm for linear optimization based on a new wide neighbourhood. CEJOR. https://doi.org/10.1007/s10100-018-0524-0

Gardijan M, Lukač Z (2018) Measuring the relative efficiency of food and drink industry in chosen EU countries using the data envelopment analysis with missing data. CEJOR. https://doi.org/10.1007/s1 0100-018-0540-0

Gaspars-Wieloch H (2017) Newsvendor problem under complete uncertainty: a case of innovative products. CEJOR 25:561. https://doi.org/10.1007/s10100-016-0458-3 
Hamedović S, Benšić M, Sabo K, Taler P (2018) Estimating the size of an object captured with error. CEJOR. https://doi.org/10.1007/s10100-017-0504-9

Jelić S, Ševerdija D (2017) Government formation problem. CEJOR. https://doi.org/10.1007/s10100-0170505-8

Kadoić N, Ređep NB, Divjak B (2018) A new method for strategic decision-making in higher education. CEJOR. https://doi.org/10.1007/s10100-017-0497-4

Kojić V, Lukač Z (2018) An alternative approach to solving cost minimization problem with Cobb-Douglas technology. CEJOR. https://doi.org/10.1007/s10100-017-0519-2

Kramarić TP, Bach MP, Dumičić K, Žmuk B, Mihelja Žaja M (2018) Exploratory study of insurance companies in selected post-transition countries: nonhierarchical cluster analysis. CEJOR. https://doi. org/10.1007/s10100-017-0514-7

Kvet M, Janáček J (2017) Fair emergency system design under uncertainty. CEJOR. https://doi.org/10.100 7/s10100-017-0507-6

Majstorović S, Sabo K, Jung J, Klarić M (2018) Spectral methods for growth curve clustering. CEJOR. https://doi.org/10.1007/s10100-017-0515-6

Marošević T, Soldo I (2018) Modified indices of political power-a case study of a few parliaments. CEJOR. https://doi.org/10.1007/s10100-017-0487-6

McCormick G, Owen G (2018) A composite game of hide and seek. CEJOR. https://doi.org/10.1007/s101 00-017-0516-5

Meszaros C (2015) The practical behavior of the homogeneous self-dual formulations in interior point methods. CEJOR 23:913. https://doi.org/10.1007/s10100-013-0336-1

Perić T, Babić Z, Matejaš J (2018) Comparative analysis of application efficiency of two iterative multi objective linear programming methods (MP method and STEM method). CEJOR. https://doi.org/10. 1007/s10100-018-0543-x

Scitovski R, Vinković M, Sabo K, Kozić A (2017) A research project ranking method based on independent reviews by using the principle of the distance to the perfectly assessed project. Croat Oper Res Rev 8(2):429-442. https://doi.org/10.17535/crorr.2017.0027

Šegota A, Cerović L, Maradin D (2017) Efficiency of municipal service providers in the Republic of Croatia. Croat Oper Res Rev 8(2):429-442. https://doi.org/10.17535/crorr.2017.0035

Targiel KS, Nowak M, Trzaskalik T (2018) Scheduling non-critical activities using multicriteria approach. CEJOR. https://doi.org/10.1007/s10100-018-0542-y

Trdin N, Bohanec M (2018) Extending the multi-criteria decision making method DEX with numeric attributes, value distributions and relational models. CEJOR 26(1):1-41. https://doi.org/10.1007/s10 100-017-0468-9

Vinkó T, Gelle K (2017) Basin Hopping Networks of continuous global optimization problems. CEJOR 25:985. https://doi.org/10.1007/s10100-017-0480-0 